\title{
Article
}

\section{D BIM: an investigation into the integration of quantity surveyors within the BIM process}

Mayouf, Mohammad, Gerges, Michael and Cox, Sharon

Available at http://clok.uclan.ac.uk/26151/

Mayouf, Mohammad, Gerges, Michael ORCID: 0000-0001-5986-7301 and Cox, Sharon (2019) 5D BIM: an investigation into the integration of quantity surveyors within the BIM process. Journal of Engineering, Design and Technology, 17 (3). pp. 537-553. ISSN 1726-0531

It is advisable to refer to the publisher's version if you intend to cite from the work. http://dx.doi.org/10.1108/jedt-05-2018-0080

For more information about UCLan's research in this area go to http://www.uclan.ac.uk/researchgroups/ and search for <name of research Group>.

For information about Research generally at UCLan please go to http://www.uclan.ac.uk/research/

All outputs in CLoK are protected by Intellectual Property Rights law, including Copyright law. Copyright, IPR and Moral Rights for the works on this site are retained by the individual authors and/or other copyright owners. Terms and conditions for use of this material are defined in the policies page. 


\title{
5D BIM: An investigation into the Integration of Quantity Surveyors within the BIM Process
}

\author{
Mohammad Mayouf - Birmingham City University, Faculty of Computing Engineering and \\ the Built Environment, Birmingham, UK
}

Michael Gerges - University of Central Lancashire, Preston, UK

Sharon Cox - Birmingham City University, Faculty of Computing Engineering and the Built Environment, Birmingham, $U K$

\begin{abstract}
Purpose: This paper aims to investigate the integration of a QS role and practice within the BIM process to enable better implementation of 5D BIM technology. It proposes the use of a 'level of development and level of detail' (LoDs) to provide a structured approach for quantity surveyors' integration within the BIM process for an improved implementation of 5D BIM technology.

Design/methodology/approach: This paper uses semi-structured interviews with quantity surveyors from academic and industry in the UK. A total of 20 face-to-face semi-structured interviews with two groups (Industrial and Academic) of 10 participants from the West Midlands region in the United Kingdom. The interview questions have focused on gaining perspectives on BIM, BIM and government protocols for the QS profession, expectations and challenges when implementing 5D BIM.
\end{abstract}

Findings: The findings show that BIM is perceived differently, inflexibility of standardising costs reduce reliability in 5D BIM and implementing of 5D BIM needs an understanding of workflow and complexity of information.

Research limitations/implications: Although the findings reveal many of the complexities that face quantity surveyors within the BIM process as well as the shortfalls of 5D BIM Technology, the results may lack generalisability. Thus, future research seeks to test the proposed framework further.

Practical implications: This paper elicits implications of shortfalls that impact the implementation of 5D BIM technology and the complexities the face quantity surveyors within the BIM process.

Originality/value: This paper reveals the need to understand the process of integrating stakeholders and their information requirements for better implementation of technologies within BIM.

\section{Key words: Building Information Modelling (BIM), Quantity Surveying (QS), Cost, Information}

\section{Introduction}

With its capabilities and momentum, Building Information Modelling (BIM) started to gain more presence within the construction industry. BIM has enabled many issues to be overcome especially with relation to management of information when compared to the traditional processes (Smith, 2014). Information within BIM are commonly described in dimensions (Ds) such as 4D (time), 5D (cost), 6D (Facility Management), 7D (sustainability) where each D is a result of the data/information dimension integrated in a BIM model (Eastman et al., 2011). According to Aouad et al. (2007), BIM supports quick automation of cost schedules such as 
Bill of Quantities (BOQ). Davidson (2009) suggests that cost analysis can be extracted at any stage, which is referred to as 5D BIM technology. As described by Smith (2014), 5D BIM is considered as an essential part of the BIM integrated project delivery approach. Thus, requiring both different ways of thinking (RICS, 2011), and more importantly, the involvement of stakeholders (Mitchell, 2012; Muzvimwe, 2011) that contribute towards the usefulness of this new approach. Many research efforts have looked into the application of 5D BIM indicating its benefits (Wong et al., 2011; Cheunga et al., 2012; Frei et al., 2013), but few have looked into its challenges (Wu et al., 2014; Luth et al., 2014), and the role of quantity surveyors (QSs) (Smith, 2016) within the process of developing 5D BIM. In other words, the main gap lies in understanding the flow of data/information following the creation of 3D models by designers, and where shortfalls potentially occur prior to the application of 5D BIM based on the quantity surveyors' perspective. It is anticipated that an understanding of these potential issues will contribute towards more solidified approach for cost-related considerations, and more importantly, emphasise the role of quantity surveyors more explicitly during the 5D BIM development process. Simultaneously, as BIM started to position itself within the curriculum of many construction-related programmes (e.g. construction management and quantity surveying), it is important to go beyond practice to take into consideration academia. This research seeks to investigate the application of 5D BIM from quantity surveyors' perspectives, taking in consideration those from both industry and academia. This requires revising of the QS-related practice, and highlighting BIM benefits and challenges for QSs.

\section{Quantity Surveying (QS): Practice and Challenges}

The roles and functions of QS operating in the traditional environment have been recognised as estimating and cost planning, procurement advice, measurement, preparation of Bill of Quantities (BOQ) and tender documentation, cost control, preparing valuations, payments, contractual claims and final accounts (Ashworth and Hogg, 2007). For quantity surveyors, the early cost estimates are their first involvement with construction projects where they assess designers' designs in terms of costs (Raisbeck and Aibinu, 2010). Nowadays, quantity surveyors use a set of rules and guidelines for measuring and pricing building works such as Standard Method of Measurement (Wu et al., 2014), and New Rules of Measurement (NRM) which consists of 3 volumes (RICS, 2014; Ashworth et al, 2014). Some QS describe measurement and quantification as a process in converting construction drawings into words and numbers in accordance with a set rule of measurement (McDonnell, 2010). The procedure in generating quantities is based on observation of drawings; it should be noted that the quality of drawings plays a major part in achieving accurate estimates (Elbeltagi, 2016).

As a profession, quantity surveyors face numerous challenges, which often arise during the design stage. A survey undertaken in New Zealand suggested that poor quality of design documentation is one of the key challenges encountered by quantity surveyors. Design drawings and specifications were in conflict, containing errors and lacking sufficient details to provide accurate cost advice (O'Brien et al., 2014; RICS, 2014). Buildability issues also arise from designs that are too complex which may lead to constructability problems. This is mainly due to the lack of understanding by designers regarding the way in which buildings are constructed in practice. The survey concluded with a recommendation that multi-disciplinary 
and collaborative approaches are required to rectify these issues (O'Brien et al, 2014). Elbeltagi (2016) suggests that the quality of drawings plays a major role towards achieving accurate estimates. Another issue is the time-consuming process when executing quantity take offs (QTOs), as it requires detailed examination of measurements (Len et al., 2005). This becomes more challenging on projects where large amounts of drawings need observing and analysing, especially when frequent changes are required, resulting in inaccuracies in estimates (RICS, 2014). In many instances, manual take-off may result in human error and even after measurements have been altered there is still no assurance they are correct (Monteiro and Martins, 2013). The introduction of technology has proved to be effective in the construction industry by assisting a wide range of QS functions. Many applications such as CATO, Master Bill, QSPro, Conquest, and bespoke packages based on Excel and developed in house (Ashworth et al, 2013).

\section{BIM for QSs: 5D BIM application outputs}

BIM provides an IT enabled approach where all disciplines can collaboratively share and work effectively (Bryde et al., 2012; Pittard and Sell, 2015). It supports providing a smooth flow of information throughout the phases of a construction project; equally the improved collaboration between stakeholders enables quick and easy information transfer by combining the work of different disciplines within a centralised model (Grilo and Jardim-Goncalves, 2010). According to Smith (2016), BIM allows quantity surveyors to spend more time in providing knowledge and expertise to the project team as the time taken to generate quantities is significantly reduced. Muzvimwe (2011) stated that BIM raises the value of QS services by offering the ability to envision, simulate and explore the impact of different design and construction scenarios through the integration of cost data, quantities, and project programmes within a BIM model. For example, clients will be able to understand and appreciate the effect different design changes will have on the project programme and budget.

In BIM, integrating the cost element is represented by the fifth dimension (5D), which for many firms, can be recognised as a competitive approach towards cost management (Smith, 2014). BIM offers the ability for QSs to take-off, count and measure directly from a regularly updated model through 5D BIM applications by linking the model to estimating software (Haque and Mishra, 2007). With the tedious task of quantification in some sense being automated and effortless, it allows QS to pay attention to and provide expertise on other project-specific factors, e.g. factorising risk and generating pricing (Autodesk, 2007). There are many research efforts that looked into 5D BIM and how it supports the role of a project cost manager (Wong et al., 2011; Cheunga et al., 2012; Frei et al., 2013). Although the primary benefits of 5D BIM are towards cost and schedule estimation (Sattineni and Macdonald, 2014; Vicosoftware, 2007), it can support facilitating other aspects. For example, Kim and Grobler (2013) suggested a way to analyse cash flows through the use of automated processes, which includes QTO, scheduling and cost estimating. Additionally, operational and lifecycle costs could also be analysed and appreciated before the building is built using collaborative procedures which in turn, can lead to cost savings (Luth et al., 2014).

The above studies along with other recent ones (e.g. Chan et al., 2018; Alhasan et al., 2017) have invested major efforts in outlining how 5D BIM can benefit cost managers/quantity 
surveyors, which can be considered as the 'outputs' from 5D BIM applications. However, these studies did not shed the light on the potential issues that occur as a result of the data/information used prior to the 5D BIM applications. In other words, majority (if not all) 5D BIM applications use 3D models (Frei et al., 2013) developed by the designers to generate outputs (e.g. QTOs, bills, etc.), but the role of quantity surveyors do not seem to be welldefined during the pre-5D BIM application process in terms of outlining the data/information required. In other words, these studies represent quantity surveyors as end-users where their role is limited to produce outputs from 5D BIM application, which can result in many inaccuracies. The following section outlines some of the challenges faced during the pre-5D BIM process. It is important to bear in mind that severity of the outlined challenges may vary depending on various factors such as the project's nature, standards incorporated, maturity of BIM implementation, the design package utilised to create the $3 \mathrm{D}$ model and type of the 5D BIM application used.

\section{BIM for QSs: Pre-5D BIM process challenges}

\section{Design Detail}

The accuracy and quality of BIM-based estimates depends on the extent to which the project has been defined to the QS (McCuen, 2009). One of the main issues encountered by quantity surveyors in the BIM environment is the lack of information presented within BIM models. As quantity surveyors are only able to cost what they have been presented with, it is very important that BIM models contain the information required by a QS to form accurate estimates. Architects and other design consultants are unwilling to provide full details of their BIM model due to the potential liability of the designer (Smith, 2016). The RICS has also highlighted that one of the initial tasks for QS is to analyse the BIM model for accuracy and information richness; however, on many occasions it has been reported that the model does not contain required information to assist with model-based measurement and quantity takeoffs (Smith, 2016). This issue has also been identified by Stanley and Thurnell (2013) who state that inadequate detail and missing information within BIM models results in design errors and inaccurate estimates. Furthermore, BIM software products are producing inadequate design information required for cost estimating purposes. However, it is important to note that designers should avoid including information as they wish due to the fact that inappropriate information could lead to incorrect decision making and unrealistic project estimates (Sabol, 2008). Wu et al, (2014) suggests BIM models that do not contain the information that QS require to form accurate cost estimates can lead to difficulties in managing and searching for required information within the model. Thus, it is crucial to initially identify information requirements to assist the cost estimation process.

\section{Standardisation}

The quantities extracted from BIM models are generated in accordance with parameters set by software vendors that do not follow a recognised method of measurement. Furthermore, the accuracy and consistency of data may be at risk as data is transmitted using different formats (RICS, 2015). A research undertaken in Australia suggested that materials are categorised by unclassified coding systems, so not all building elements are classified under the same code. This again, results in problems with data quality. The research recommended that the formation of a standardised coding system may be required to improve data accuracy and 
reliability (Kim and Park, 2016). Data generated through the quantification process is very rarely given in a format suitable for pricing (McCuen, 2009). Smith (2016) revealed that the lack of consistent modelling standards leads to quantity surveyors having to conform to several approaches which has a negative impact, resulting in inconsistencies and inaccuracies. The use of New Rules of Measurement provides a reliable and consistent approach to cost estimating and the RICS are in the process of developing international standards that conform to a recognised method of measurement as guidance is required to improve BIM implementation (RICS, 2014).

\section{Skills and Training}

The adoption of BIM has been mandated in the UK since 2016 where all government funded projects must implement BIM procedures (RICS, 2014); however, a survey undertaken by a UK law firm have suggested it is unachievable (Fitzpatrick, 2014). Some construction firms may not be able to financially fund the introduction of BIM within their firms as it involves education and training of their staff members which requires substantial time and cost commitments from QS firms. The education aspect of BIM may be assisted by universities teaching graduates the foundation knowledge required before entering the industry (Smith, 2016).

Despite BIM having its benefits, improvement and development is still required for better implementation. It can be argued that through the implementation of BIM, designers should now design to cost. Essentially BIM implementation should provide a rich data model for quantity surveyors to form accurate estimates through collaboration and smooth flow of data/information from an early stage. This paper aims to provide a holistic insight into challenges that QSs is face when implementing BIM within the UK, and how they should be incorporated within BIM processes for an effective implementation of 5D BIM.

\section{Research Methodology}

This study used a qualitative approach conducting 20 face-to-face semi-structured interviews with two groups of 10 participants from the West Midlands region in the United Kingdom. The first group are based in academic environments, which included lecturers and researchers with quantity surveying background, and mainly focusing on measurement, estimation, costing and procurement routes. The other 10 participants are quantity surveying practitioners who work for contractors or consultancies where majority have used 5D BIM applications (mainly CostX) and very few did not utilise 5D applications but are aware of its functionalities and capabilities. It is important to indicate that the participants' experiences with 5D BIM have differed where, for this research, this will significantly allow the respondents to discuss and explore further issues, which they feel are important (Clifford et al., 2016). This will support stipulating a holistic insight into various gaps, which affect the implementation of 5D BIM both from research and practice perspectives. More importantly, the findings can potentially draw some of the issues, which prevent gaining full potential of 5D BIM benefits in a construction project. The interview questions have commenced by gaining the participants' perspectives on BIM. It then inquired into BIM and government protocols for the QS profession, and finally expectations and challenges when implementing 5D BIM. Data collection was conducted using face-to-face interviews where responses were audio tapped then transcribed. Few respondents were interviewed using the phone and 
responses were instantly typed. In order to capture the main findings, authors have identified a number of keywords in order to draw the key concepts that respond to the gap being tackled in this research. The keywords included BIM, 5D BIM, BIM process and 5D BIM challenges. The findings are structured using thematic analysis, as this will support providing a more robust argument for further implications (Braun and Clarke, 2006). This will also allow emphasising the agreements and potential inconsistencies between the responses received from quantity surveying practitioners and those who are in academia.

As this research seeks to propose a way of better implementation of 5D BIM, the findings resulted from thematic analysis were fed back to most participants and a framework was developed using focus group method. Therefore, two focus group sessions (one for QS practitioners and another for participants from academia) were conducted to gather feedback from the participants within this study to propose an effective way of handling the data/information required prior to the application of 5D BIM. Each focus group included 6-8 participants where the main topics were based on the findings and analysis from the conducted interviews, which are discussed later in the paper (under discussion and practical implications section). Following the responses gathered from the focus group discussions, an approach was recommended in order to understand the data/information flow for an enhanced implementation of 5D BIM.

\section{Results and Analysis}

For the purpose of clarity, the data gathered using interviews are tabulated where responses are categorised based on both the academic and industry groups. From the interviews, it was found that majority of the academic-based participants have not had experience with 5D BIM, or incorporating it as part of the teaching curriculum, hence most responses are based on their personal experiences and research background. As for the industry-based participant, they elaborated more on the issues they faced when implementing 5D BIM, highlighting challenges and recommendations. Table 1 contains quotations extracted from the responses on the interviews.

Table 1: Extracted quotations from the interviews conducted with research participants

\begin{tabular}{|l|l|}
\hline Aspect investigated & Quotations received \\
\hline Perspectives on BIM & $\begin{array}{l}\text { "managing the information created" "producing information that } \\
\text { enables better delivery of construction project" "creating a } \\
\text { process to manage and exchange information" "An information } \\
\text { management tool" "Manage variety of data and information in a } \\
\text { structured way" "More like Building Information Management" } \\
\text { (academia) }\end{array}$ \\
$\begin{array}{l}\text { "process that promotes better collaboration" "virtual tool that } \\
\text { provide more integrated process" "process of linking 3D } \\
\text { models to other construction aspects" "a coordinated process } \\
\text { that allows better collaboration" "A more capable process of } \\
\text { managing information through the use of advanced IT" "A } \\
\text { process that should involve different stakeholders }\end{array}$ \\
\hline
\end{tabular}




\begin{tabular}{|c|c|}
\hline & $\begin{array}{l}\text { collaboratively" } \\
\text { (industry) }\end{array}$ \\
\hline $\begin{array}{l}\text { BIM for the QS } \\
\text { Profession }\end{array}$ & $\begin{array}{l}\text { "Challenge has been to produce accurate estimations" } \\
\text { "Mostly any quantification that can be extracted, which saves } \\
\text { time especially during tenders" "BIM is beneficial in terms of the } \\
\text { speed at which early cost estimates can be derived" "QS must } \\
\text { engage with it for it to be beneficial" } \\
\text { (academia) } \\
\text { "it quicker for the QS to price up a BQ and therefore being able } \\
\text { to be more productive" "improve the efficiency (QTO) through } \\
\text { automation and reduce the need for the timely outdated manual } \\
\text { take off" "It would all depend on who entered the data and how } \\
\text { competent they are" "depend on how the data is embedded and if } \\
\text { they are exported within the same software or another 5D } \\
\text { specialist software as well as the file format" "This depends on } \\
\text { the project and the skills and competencies of the designers. } \\
\text { More often though the supply chain falls behind on the relevant } \\
\text { geometrical and semantic level of detail with BIM" } \\
\text { (industry) }\end{array}$ \\
\hline $\begin{array}{l}\text { Role of Government } \\
\text { protocols }\end{array}$ & $\begin{array}{l}\text { "from what I have seen there isn't much documents out there } \\
\text { that give contractors and consultants a good guide } \\
\text { line/benchmark, which makes it difficult to know whether what } \\
\text { you are doing is 'correct' and conforms with requirements } \\
\text { whether that be internal or external" "in order to effectively use } \\
\text { quantification a classification system needs to be in place" "there } \\
\text { is a clear oversight with the Publicly Accessible Protocols for } \\
\text { estimators" "I believe the industry is still playing catch up with } \\
\text { the new technology that's being proposed" } \\
\text { (industry) }\end{array}$ \\
\hline $\begin{array}{l}\text { Challenges faced } \\
\text { when implementing } \\
\text { 5D BIM }\end{array}$ & $\begin{array}{l}\text { "teething issues within the software implementation, and } \\
\text { changing of working practice" "Ultimately depends on the person } \\
\text { who you're training" "integration and upskilling of relevant } \\
\text { stakeholders in the process of BIM implementation. With a } \\
\text { particular focus and emphasis on the supply chain" "Architects } \\
\text { are normally good with modelling software, however, with QS its } \\
\text { new and they need to be trained to use this new software for it to } \\
\text { benefit them" "QS's have limited understating of the production } \\
\text { of a BIM model and how a QS can make full use of the model } \\
\text { and the process" "check if there is sufficient information in the } \\
\text { model at the different stages" "From a constractors point of view } \\
\text { possibly, if its estimating stage when bidding for a job, the use of } \\
\text { the model could be quite helpful, as it would allow them to } \\
\text { export schedules do measurements etc. However it would depend } \\
\text { on who drew the model as if its is at the early stages large } \\
\text { amounts of detail could be missing out of the model, so your } \\
\text { costs could be way out which means you could potentially lose } \\
\text { the job" "I think it would take a lot of getting used to moving } \\
\text { from traditional to modern costing with the new technology" }\end{array}$ \\
\hline
\end{tabular}




\begin{tabular}{|l|l|}
\hline & $\begin{array}{l}\text { "BIM has its own classification of objects, which is Uniclass, and } \\
\text { this is difficult to be reliable when pricing" } \\
\text { (industry) }\end{array}$ \\
\hline $\begin{array}{l}\text { Recommendations } \\
\text { for 5D BIM }\end{array}$ & $\begin{array}{l}\text { "Seek expert advice and test out on pilot projects or previous } \\
\text { projects where a comparison between traditional practices can be } \\
\text { made" "Depending on what contract you go into between } \\
\text { yourself and the Client/Customer" "ensure BIM is implemented } \\
\text { and time is allowed to execute the system" "Seek better } \\
\text { integration and upskilling of relevant stakeholders in the process } \\
\text { of BIM implementation with a particular focus and emphasis on } \\
\text { the supply chain" "virtually every project, the 2D and PDFs are } \\
\text { the contractual documents. So technically you should only be } \\
\text { using those to "price' from I suppose" } \\
\text { (industry) }\end{array}$ \\
\hline
\end{tabular}

\section{Quantity Surveyors' perspectives on BIM}

It can be argued that both background and experience have influenced different participants' perspectives on BIM. Interviewees from the academic-based group claimed that BIM is about engaging with the information and creating a process of collating and inputting information into a building model. This showed that information is occupying the major concern based on those based in academic environments. This could be due to several reasons, which includes the intensity of information that a QS need to handle at an early stage. Another reason is the complex nature of information itself, which must be consistent in order establish an effective communication to the clients. Also, the fact that academic-based QS, are much aware of the current challenges that face the implementation of BIM within construction projects. Interviewees from the industry-based group argued that introducing a new process for collaboration and software packages that support generating costs promptly are what makes BIM effective for a construction project. Collaboration was highlighted as a major issue, as QS are often not involved in the BIM process. Also, the anticipation of BIM automated processes in terms of generating rapid results. Based on both groups' responses, it can be realised that both the process to manage information and BIM applications to generate costs form the QS's top priorities. On a bigger picture, this shows that understanding of BIM in academia and industry requires careful distinction. In academia, teaching BIM follows an information driven approach whereas in industry, working with BIM requires a process change approach. The 'process change' forms a more complex challenge, because it covers people, information and technology. Hence, more collaboration between academia and industry needs to be in place in order to educate BIM in an effectively more integrated approach that acknowledges information complexity and process change.

\section{D BIM for Quantity Surveying Profession}

Although the literature has provided an overview of BIM benefits and issues for QS profession, the findings highlighted further insights into the current application of BIM for QS. A common thread amongst both groups (academic and industry based) is the automated nature of BIM applications and how it adds value to the QS profession. The majority of the participants stated that many BIM applications can generate QTOs, which can both save time and allow for further value adding by the QS to a project. Many of the academic-based participants claimed that advanced visualisations should enable a QS to identify missing 
information by visually observing the BIM model. However, they highlighted that current LOD (level of detail) might form an obstacle when trying to detect missing information.

Most of the industry-based respondents claimed that 5D BIM needs to be explicitly positioned in terms of information requirements and the involvement of QS at various stages in a project. Reflecting on their practices, they added that they only receive information from the designer, and only supply to them what is requested to fulfil the required information for the BIM Model. In other words, QS practitioners assume that the BIM process is fundamentally dominated by BIM Managers/Coordinators who often are the designers. Simultaneously, some academic-based respondents stated the need to establish an information requirement and exchange route in order to solidify the future place of BIM's fifth dimension (5D) to be more effectively integrated within the BIM process at early stages.

\section{Implementation challenges of 5D BIM}

This section further discusses the challenges faced with implementing 5D BIM. As this section discusses implementation, responses were mainly gathered from the industry-based participants. The first highlighted challenge, which was brought up by most respondents, is the lack of understanding BIM workflow. They described a lack of training and skills as well as ambiguous involvement in the BIM process as being the main causes that lead towards poor understanding of BIM workflow. Another identified challenge when implementing 5D BIM is the complexity of identifying missing information from a BIM Model. For example, few participants stated that, with a 3D BIM model, missing information is not easily identifiable. They elaborated on this issue by indicting the shortcomings resulting from working in silos, and how poor communications can lead to providing inefficient information. Hence, they stated that the involvement of QS within the BIM process at an early stage is crucial and can perhaps avoid various conflicts and potential misleading information. Another challenge raised by the respondents is the clash of, in terms of implementation, between traditional methods and BIM way of work.

Many QS practitioners stated that it becomes nearly impossible to establish a standardised approach when working in BIM environment. They added that this is because BIM classifies objects as "Uniclasses" and generate a bill based on it. However, to provide a well-informed bill, appropriate standards must be used so that it can be communicated effectively and consistently to the client. Hence, many of the respondents stated that, in many projects where BIM was implemented, costs were initially generated using BIM Models, but the final bill was prepared traditionally using 2D sketches and PDFs to ensure consistency and reliability of the overall costs. In terms of the future of 5D BIM, it was stated that implementing 5D on previously done projects can be beneficial to recognise and benefits and shortcomings of using the technology. Also, it is important to ensure that all stakeholders within the supply chain of a project are involved to ensure a consistent flow of information. The respondents concluded that 5D BIM is yet to be fully understood, which makes its implementation a major challenge that need to be addressed in order to gain its full potential within the BIM process.

Table 2: Summary of findings from the QS practitioners vs. QS academics with respect to the themes used for analysis 


\begin{tabular}{|c|c|c|}
\hline Theme & QS Practitioners & QS Academics \\
\hline $\begin{array}{l}\text { Quantity } \\
\text { Surveyors' } \\
\text { perspectives on } \\
\text { BIM }\end{array}$ & $\begin{array}{l}\text { Introducing a new process for } \\
\text { collaboration and software packages } \\
\text { that support generating costs promptly } \\
\text { are what makes BIM effective for a } \\
\text { construction project. } \\
\text { - Working with BIM requires a process } \\
\text { change approach. }\end{array}$ & $\begin{array}{l}\text { BIM is about engaging } \\
\text { with the information } \\
\text { and creating a process } \\
\text { of collating and } \\
\text { inputting information } \\
\text { into a building model. } \\
\text { - In academia, teaching } \\
\text { BIM follows an } \\
\text { information driven } \\
\text { approach. }\end{array}$ \\
\hline \multirow{2}{*}{$\begin{array}{l}\text { 5D for Quantity } \\
\text { Surveying } \\
\text { Profession }\end{array}$} & \multicolumn{2}{|l|}{ Many BIM applications can generate QTOs } \\
\hline & $\begin{array}{l}\text { 5D BIM needs to be explicitly } \\
\text { positioned in terms of information } \\
\text { requirements and the involvement of } \\
\text { QS at various stages in a project. } \\
\text { - BIM process is fundamentally } \\
\text { dominated by BIM } \\
\text { Managers/Coordinators who often are } \\
\text { the designers. }\end{array}$ & 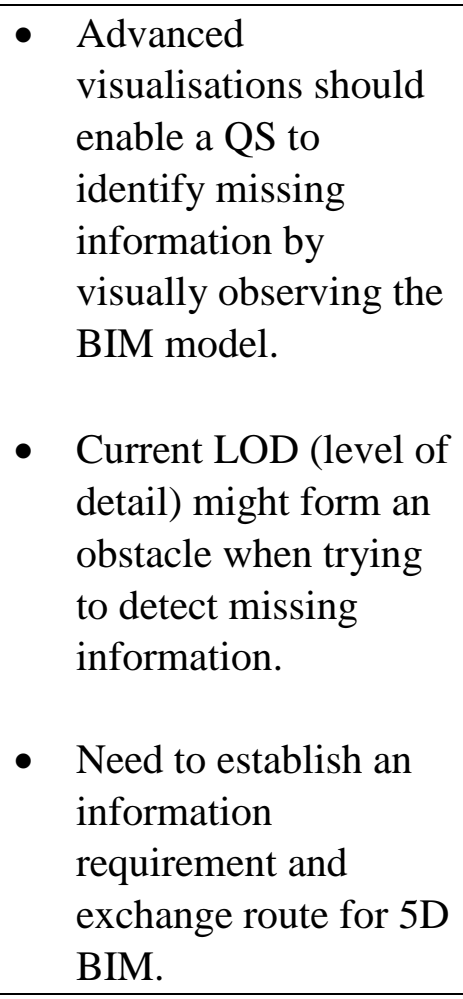 \\
\hline $\begin{array}{l}\text { Implementation } \\
\text { challenges of } \\
5 \mathrm{D} \text { BIM }\end{array}$ & 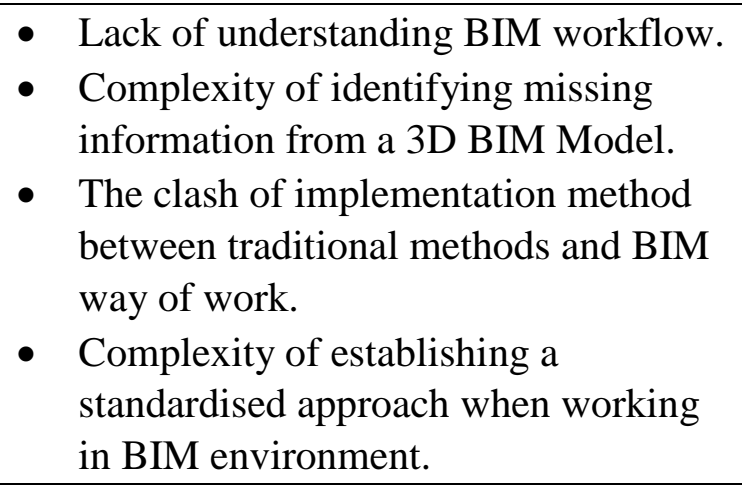 & \\
\hline
\end{tabular}

\section{Discussion and practical implications}


Based on the presented findings, it can be stated that understanding BIM workflow is needed to achieve a better resonance of 5D BIM implementation within a construction project. According to Graham (2015), and based on a survey that involved 1200 people, the importance of perceiving both requirements and understanding of BIM Workflow are essential for better implementation. BIM is currently often utilised as a tool or software to generate information, which in many instances cannot support the primary objective of a project. More importantly, establishing a strategy to effectively communicate decisions amongst different stakeholders can support the BIM process and minimise potential errors (Azhar, 2011). Based on the findings, quantity surveyors need to be more engaged with the BIM process collaboratively with the designers. This will allow both an enhanced coordination and better collaboration with the designers who seem to be driving the workflow in BIM. Smith (2016) has raised the importance of building a trust relation between the designers and quantity surveyors, as often designers share limited versions of their BIM models. This is important, as enhancing this will support realising the value of implementing and minimise errors and possible clashes. Lu et al. (2017) proposed a framework that provide more accurate solutions for better implementation of 5D BIM. Although it considers many of the fixed and variable costs, as well as indicating the information needed at various stages, it did not show where a QS can be involved and possible iterations where cost analysis are created at various stages during the development of a BIM Model. It can be argued that, with new quantity surveyors looking to enter the construction industry, learning about BIM at university level may help to better prepare graduates and improve awareness of the workflow within BIM. For quantity surveyor's already in the industry, in-house support may be required however this may come at a cost to the firm, hence research in this direction is desired.

\section{The dilemma of 'data/information' in 5D BIM}

Based on the analysis, information can be argued as the major issue facing both the current and future implementation of BIM within the construction industry. Referring back to the findings, on the one hand, most academic-based respondents highlighted that BIM is meant to drive an effective way of collating and managing information from different disciplines. One of the ways of understanding this holistically is the ability to identify the involved stakeholders' information requirements. Although predominantly due to the nature of construction projects, identifying the necessary information becomes more accurate and useful as the project progresses. Feng et al. (2012) proposed an 'information integration sphere' framework, which support the integration of different stakeholders' roles and responsibilities. One of the primary outcomes from their proposed framework is the production of a data requirements report for each stakeholder, but it did not highlight the challenges resulted from the automated processes within the BIM environment.

The complexity of information requirements differs for each stakeholder within a construction project. Many of the industry-based respondents stressed the sensitivity of the cost element, and the danger of making it BIM process-dependent. Hence, it can be claimed that the implementation of 5D BIM is yet to gain its conceptual domination in representing cost-related aspects within BIM. This is perhaps due to the limitation of cost-related information that can be obtained from a 3D BIM Model, which was a highlighted issue by the QS practitioners within the study. Furthermore, reflecting on their industrial experiences, and to overcome this limitation, most of the respondents highlighted the need for an approach that 
links traditional procedures and BIM processes. To illustrate this, figure 1 the dilemma and complexities related to information within the BIM process. The complexity of this dilemma initiates, prior to the implementation of 5D BIM, from the required information that need to be supplied by the quantity surveyor/cost manager (see figure 1) to fulfil the required information for the BIM Model developed by the designer (BIM Manager). This includes specifications, early cost estimates and measurements. However according to the respondents in this research, they are always influenced by traditional methods as well as standards when providing the information requirement. Based on the quantity surveyors' traditional practices, the required information often needs additional information (see figure 1), which often are extra details and non-automated information (see figure 1) such as existing standards (e.g. NRM) by the government. For the quantity surveyors, this information is essential in order to ensure effective cost management after completion of the BIM Model.

Due to the nature of construction projects, changes occur on a continuous basis, which results in various versions of BIM Models (see figure 1). In order to produce a cost bill, 5D software application such as CostX, Vicosoftware, etc. is needed. Regardless of the interoperability issues, producing accurate cost bills is influenced by the coordination process between the BIM Manager and quantity surveyors in terms of providing accurate updates of changes that occur. Hence, according to the participants in this research, the use of 5D BIM is often limited to the early stages, but as the projects progresses, 2D and PDFs are used to produce more accurate bills. A study by Olatungi (2014) suggested the use of RIBA plan of work to support cost estimation, allocating software applications that support the process throughout all RIBA stages, but the study has limited the view to estimators who only know how to utilise BIM applications.

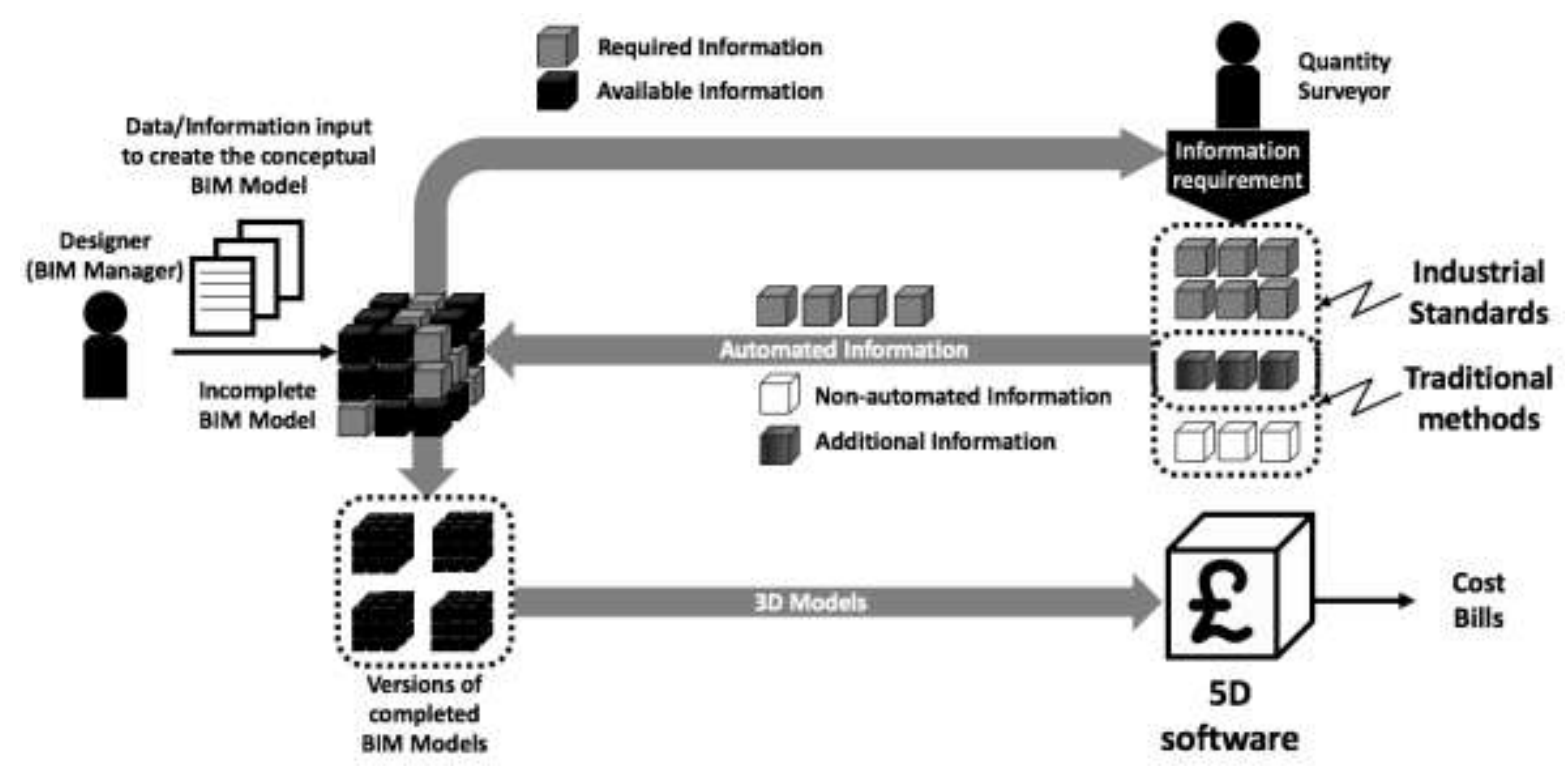


Figure 1: The dilemma of information within the BIM process, and how many information requirements by the quantity surveyors cannot be integrated within the BIM Model.

\section{LoD to structure cost information}

Based on the previous sections, understanding the nature of information (non-automated and additional) forms a major challenge towards a more effective implementation of 5D BIM technology. Therefore, focus groups were used to gather feedback from the participants within this study to propose an effective way of handling the information that often are complex to be integrated within the BIM process. Two focus group (industry-based and academic-based participants) sessions were conducted. Each group was briefed with the analysis presented in the previous section (see figure 1). Although both groups comprised of quantity surveyors, their perspectives towards proposing an ideal solution to overcome the complex nature of information were different. The industry-based group were after a solution that can support better implementation of 5D BIM technology whereas the academic-based group anticipated a structured approach that support incorporating current industrial standards such as NRM.

As a result, the researchers in this paper proposed the use of level of development and detail (LoD) as a way to provide a structured approach for better implementation and understanding of 5D BIM. This is because both LoDs (development and detail) can support understanding both the necessary details and amount of information required (Bedrick, 2013). A recent study by Wood et al. (2014) used LoD as a costing mechanism for structural designs and proposed fuzzy algorithms that match BIM objects with cost data.

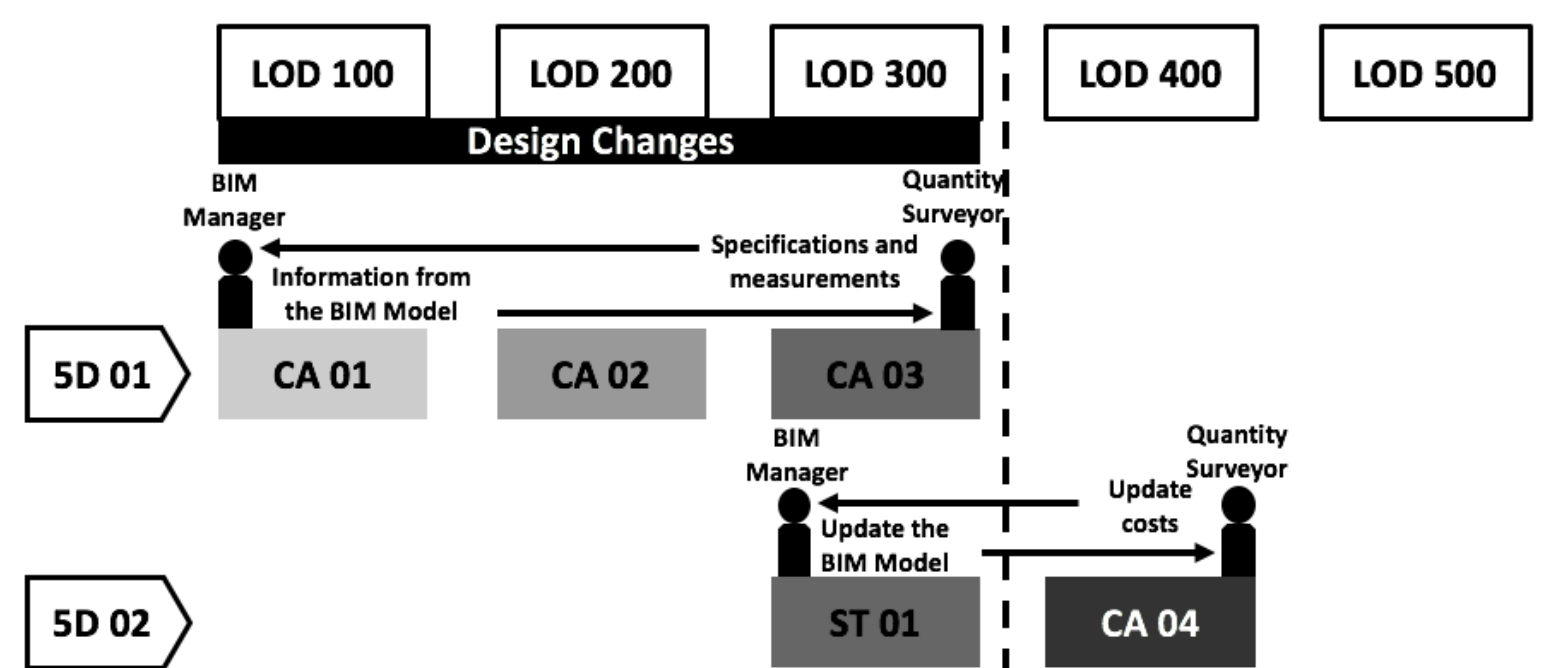


Figure 2: The proposed LoD-based approach to tackle design changes and incorporating government standards.

The majority of the participants highlighted that design changes and incorporating the government standards are the biggest challenges faced when working with BIM. Collaboratively, a framework (see figure 2) was proposed that support situating both design changes and standards with respect to the LoD. It is important to indicate that the proposed approach may slightly differ depending on the procurement route. For the purpose of this paper, traditional route was used as an example to demonstrate use of the proposed approach. It can be claimed that the proposed approach can support providing better opportunity for quantity surveyors to involved in the process, and a more structured method to understand the flow of information. From figure 2, 5D will be implemented in three levels (described in table 2): 5D 01, 5D 02 and 5D 03. In 5D 01, a continuous communication should take place between the quantity surveyor and BIM Manager. At this level, the quantity surveyor's involvement will be, followed by the conceptual BIM model by the BIM Manager, in terms of providing cost analysis (QTOs) for high level elements especially structural, MEP (Mechanical, Electrical and Plumbing) elements, and building envelope as part of the architectural elements. At this stage, the quantity surveyor ensures that the right specifications and measurements for the high elements have taken place before the construction phase. This will support avoiding the production of heavy BIM models, easier detection of changes in 5D software applications and quicker cost analysis from the BIM Model. In 5D 02, followed by confirmation of the high-level elements, the standardisation process begins where the quantity surveyor starts to align the high-level elements with the government standards (NRM 2). At this level, followed by the standardisation of high-level elements, the BIM Manager begins to add more details to the model, which implies that an updated cost analysis (CA 04) will be produced. It is important to indicate that changes should be to the minimal at this level, as this will be during the construction phase. In 5D 03, which should take place at an advanced point during the construction phase, after agreeing the FFE (fixed furniture and equipment) elements, second phase of the standardisation process takes place. At this stage, the participants stated that importance of incorporating standards related to post-construction phase such as NRM 3 (quantification of maintenance work) and SFG20 (planned maintenance work), as this will be beneficial to maintain longerterm value and reduce future costs. 
Table 3: 5D stages from the proposed LoD-based approach and their description of activities

\begin{tabular}{|l|l|}
\hline Stage & Description \\
\hline 5D 01 & $\begin{array}{l}\text { CA: Cost Analysis } \\
\text { CA 01 - 03: initial cost analysis of high level elements from the BIM Model takes } \\
\text { place. At this stage, design changes occur at a high frequency, thus communication } \\
\text { between the quantity surveyor and the BIM Manager is vital in order to ensure } \\
\text { accurate information of required specifications and measurements. }\end{array}$ \\
\hline 5D 02 & $\begin{array}{l}\text { ST: Standards } \\
\text { ST 01: First phase of standardisation using NRM 2, which focuses on high level } \\
\text { construction elements produced by the BIM model. The reason it is done after CA } \\
\text { 03 is the uncertainty of design changes that often occur from LOD 100 - 300. } \\
\text { CA 04: Cost analysis produced followed by the initial standardising of the cost } \\
\text { analysis produced at LOD 300 (CA 03). At this stage, NRM 2 (accurate } \\
\text { description and quantification of a construction elements) is incorporated by the } \\
\text { quantity surveyors in order to provide useful meanings beyond the BIM } \\
\text { application's classification (Uniclass) of construction elements. }\end{array}$ \\
\hline 5D 03 & $\begin{array}{l}\text { ST 02: Second phase of standardisation using NRM } 3 \text { and SFG20 followed by the } \\
\text { CA 04, which takes place at a later stage during the construction phase. At this } \\
\text { stage, it is expected that minimal to none design changes will be made. } \\
\text { CA 05: this is the final cost analysis after incorporating NRM 3 and SFG20, which } \\
\text { are related to maintenance work. It is important to indicate that there is no formal } \\
\text { approach or a specific software package that can be used to incorporate these } \\
\text { standards in BIM, thus further research efforts are needed. }\end{array}$ \\
\hline
\end{tabular}

It is important to indicate that, in addition to the standards proposed in table 2, other classification systems could be incorporated such as OmniClass Construction Classification system, ICE CESMM, SMM7, MasterFormat and UniFormat. In a recent study, RICS (2014) stated that it is important to establish a broader vision as well as behavioural changes from all stakeholders to collaborate on the BIM platform with a need for an effective system and industrial approach. Thus, it is anticipated that the proposed LoD-based approach in this paper can potentially support overcoming both the challenges for implementing 5D BIM effectively, and more significantly, add another foundation on establishing an approach that benefit both industry and academic establishments in understanding BIM.

\section{Conclusion and future work}

This study provided a way for better implementation of 5D BIM technology from the quantity surveyors' perspective. The literature showed that there are many challenges faced with relation to $5 \mathrm{D}$ BIM in the construction industry, which mainly related to design detailing, standardisation and skills required. Although there are recent studies that highlights 5D BIM challenges, most of these studies provided recommendations, which do not incorporate the quantity surveyors' perspectives. In-depth interviews were conducted with quantity surveyors from practice and academia in order to gain a holistic understanding of 5D BIM and how it can be improved. Analysis showed that there is a lack of understanding the 
position of a quantity surveyor within the BIM workflow and incorporating the information they require than the information required by the model are the main challenges facing the implementation of 5D BIM. LoD was suggested to provide a structured BIM-based solution for better implementation of 5D BIM technology. Using focus group method, it was found that design changes and incorporating government standards can provide a structured and practical approach to understand the implementation of 5D BIM more effectively. Future studies seek to implement the proposed approach as well as gaining further insights into its limitations within different procurement routes.

\section{References:}

Alhasan, S., Kumar, B. and Thanikal, J. (2017) 'Effectiveness of implementing 5D functions of Building information moeling on professions of quantity surveying - A review', International Journal of Civil Engineering and Technology, 8(5), pp. 783 - 800.

Aouad, G., Lee, A. and Wu, S. (2007) Constructing the Future: nD Modelling. Oxon: Taylor and Francis.

Ashworth, A., \& Hogg, K. (2007) Willis's Practice and Procedure for the Quantity Surveyor, (12th ed.). Oxford: Blackwell Publishing Ltd.

Ashworth. A, Hogg. K, Higgs. C (2014) 'How can BIM support the new rules of measurement (NRM1)', New rules of measurement, (4.2), 29.

Autodesk (2007) BIM and Cost Estimatin: Model Based. Available at: http://images.autodesk.com/apac_grtrchina_main/files/aec_customer_story_en_v9.pdf. (Accessed on: 1st June 2017).

Bedrick, J. (2013) The Model Development Specification (MDS): A Lnaguage and Process for Defining Building Information Model Milestones and Deliverables. AEC Process Engineering.

Braun, V. and Clarke, V. (2006) 'Using thematic analysis in psychology', Qualitative Research in Psychology, 3(2). pp. 77-101.

Chan, I. Y. S., Liu, A. M. M. and Chen, B. (2018) 'Management Strategies for 5D-BIM adoption in Hong Kong', Proceedings of the $21^{\text {st }}$ International Symposium on Advancement of Construction Management and Real Estate, pp. 1023 - 1039.

Cheunga, F., Rihana, J., Taha, J., Duceb, D. and Kurula, E. (2012) 'Early stage multi-level cost estimation for schematic BIM models', Automation in Construction, 27, pp. 67-77.

Clifford, N., Cope, M., Gillespie, T., French, S. (2016) Key Methods in Geography. 3rd ed. London : Sage Publications.

Davidson, A. (2009) A Study of the Deployment and Impact of Building Information Modelling Software in the Construction Industry. Available at: http://www.engineering.leeds.ac.uk/eengineering/documents/AndrewDavidson.pdf (Accessed on: 29th April 2017). 
Eastman, C., Teicholz, P., Sacks, R. and Liston, K. (2010) BIM handbook: A guide to building information modelling for owners, managers, designers, engineers and contractors, $2^{\text {nd }}$ Edition. New Jersey: John Wiley and Sons.

Feng, C-W., Mustaklem, O. and Chen, Y-J. (2011) 'The BIM-Based Information Integration Sphere For Construction Projects', Proceedings of the $28^{\text {th }}$ ISARC, Seoul (Korea), pp. 156-161.

Fitzpatrick. T, (2014) Industry fears over government 2016 BIM mandate. Available: https://www.constructionnews.co.uk/innovation/bim/industry-fears-over-government2016-bim- mandate/8658734.article (Accessed 20th 2016).

Frei, M., Mbachu, J. and Phipps, R. (2013) 'Critical success factors, opportunities and threats of the cost management profession: the case of Australasian quantity surveying firms', International Journal of Project Organisation and Management, 5 (1).

Grillo, A. and Jardim-Goncalves, R. (2010) 'Value Proposition on Interoperability of BIM and Collaborative Working Environments', Automation in Construction, 19, pp. 522 528.

Haque, M. E. and Mishra, R. (2007) '5D virtual construction: Designer/constructors perspective', $10^{\text {th }}$ Internatioanl Conference on computer and Information Technology, Dhaka, Bangladesh, pp. $1-4$.

Kim, H. and Grobler, F. (2013) 'Preparing a construction cash flow analysis using Building Information Modeling (BIM) technology', KICEM Journal of Construction Engineering Project Management, pp. 1-9.

Kim, K. P. and Park, K. S. (2016) 'Implication of Quantity Surveying Practice in a BIMenabled Environment', NZIQS/PAQS Conference Programme and Proceedings, Christchurch, New Zealnd, pp. $1-11$.

Luth, G. P., Schorer, A. and Turkan, Y. (2014) 'Lessons from Using BIM to Increase Design-Construction Integration', Practice Periodical on Structural Design and Construction, 19, pp. $103-110$.

McCuen, T. (2009) Cost Estimating in BIM: The Fifth Dimension. Available: http://constructionadvisortoday.com/2009/11/cost-estimating-in-bim-the-fifthdimension.html (Accessed on: 20th May 2017).

Mitchell, D. (2012) '5D Creating Cost Certainty and Better Buildings', RICS Cobra Conference. Las Vegas.

Muzvimwe, M. (2011) 5D BIM Explained. Available at: http://www.fgould.com/uk/articles/5d-bim-explained/ (Accessed on: 28 ${ }^{\text {th }}$ March 2017).

Olatunji, O. A. (2014) 'Perspectives on Modelling BIM-enabled Estimating Practices', Australian Journal of Construction Economics and Building, 14(4), pp. 32 - 53. 
RICS (2011) Building Information Modelling Survey Report, Building Cost Information Service (BCIS). London: RICS.

RICS (2014) How Can Building Information Modelling (BIM) Support The New Rules of Measurement (NRM1). London: RICS.

RICS (2015) Surveyor skills shortage approaching critical level, warns RICS. Available at: http://www.constructionmanagermagazine.com/news/surveyor-sk2ills-shor6tageappr7oaching-critical/ (Accessed on: $17^{\text {th }}$ May 2017).

Sabol, L. (2008) Challenges in Cost Estimating with Building Information Modeling: Challenges in Cost Estimating with Building Information Modeling. Washington: Design + Construction Strategies.

Sattineni, A., Macdonald, J.A. (2014) '5D-BIM: A Case Study of An Implementation Strategy in the Construction Industry', The 31st International Symposium on Automation and Robotics in Construction and Mining (ISARC 2014), Sydney, Australia.

Smith, P. (2014) 'BIM \& the 5D Project Cost Manager', Procedia-Social and Behavioural Sciences, 119, pp. 475 - 484.

Smith, P. (2016) 'Project Cost Management with 5D BIM', Procedia-Social and Behavioural Sciences, 226, pp. 193 - 200.

Stanley, R. and Thurnell, D. (2013) 'Current and Anticipated Future Impacts of BIM on Cost Modelling in Auckland', Proceddings of $38^{\text {th }}$ AUBEA International Conference, Auckland, New Zealand, pp. 20 - 22.

Vicosoftware (2007) Oy Alfred A. Palmberg Ab Varma Salmisaari Project. Vico Software, Inc.

Wong, K.A., Wong, F.K. \& Nadeem, A. (2011) 'Building information modelling for tertiary construction education in Hong Kong', Journal of information technology in construction, February 2011, 16, pp. 467 - 476.

Wood, J., Panuwatwanich, K. and Doh, J-H. (2014) 'Using LOD in structural cost estimation during building design stage: Pilot study', Procedia Engineering, 85, pp. 543 552.

Wu, S., Wood, G. and Ginige, K. (2014) 'A Technical Review of BIM Based Cost Estimating in UK Quantity Surveying Practice, Standards and Tools', ITCon, 19, pp. 534 $-562$. 